\title{
Design and Analysis of Carbon/Epoxy Composite Tubular Parts
}

\author{
Paul Bere ${ }^{1, a}$, Ovidiu Nemeș ${ }^{2, b}$, Cristian Dudescu ${ }^{3, c}$, \\ Petru Berce ${ }^{1, d}$, Emilia Sabău ${ }^{1, e}$ \\ ${ }^{1}$ Faculty of Machine Building, Technical University of Cluj-Napoca, B-dul Muncii, Nr. 103-105, RO- \\ 400641, Cluj-Napoca, Romania \\ ${ }^{2}$ Faculty of Materials and Environmental Engineering, Technical University of Cluj-Napoca, B-dul \\ Muncii, Nr. 103-105, RO-400641, Cluj-Napoca, Romania \\ ${ }^{3}$ Faculty of Mechanical Engineering, Technical University of Cluj-Napoca, B-dul Muncii, Nr. 103- \\ 105, RO-400641, Cluj-Napoca, Romania. \\ abere_paul@yahoo.com (corresponding author), bovidiu.nemes@sim.utcluj.ro, \\ cmircea.dudescu@rezi.utcluj.ro, dpetru.berce@tcm.utcluj.ro, eemilia.sabau@tcm.utcluj.ro
}

Keywords: Composite materials, Carbon fiber/epoxy, Pipes, Finite Element simulations.

\begin{abstract}
The paper presents a design and analysis methods of carbon /epoxy composite tubular parts. Testing and analytical computations, based on classical laminated plate theory, of the proposed and manufactured material delivered the engineering constants that have been used in the finite element simulations of two important safety tests for the handlebar (bending and torsion). The experimental results obtained for lateral bending test (critical test) are in agreement with the finite element simulations.
\end{abstract}

\section{Introduction}

Used in medical, military, performance sports, spatial domains or race cars building, composite materials get to be used in our everyday life. With mechanical and physical behavior characteristics well in excess of those exhibited by conventional high-volume materials such as steels and aluminum alloys, the reinforced composites have contributed significantly to the heightened performance of sports. Manufacturing of reinforced composite bicycle parts (frames, wheels, bar ends, handlebars and seat posts) has been significantly increased in the last decade. Most of the composite parts of a bicycle are tubes. From the point of view of obtaining the tubes from fibers reinforced polymer (FRP), the existent obtaining technologies mentioned in the scientific literature are the filament winding or pultrusion [1-3].

There are few scientific articles dealing with analysis of composite tubes as part of a bicycle. Most of the studies $[4,5]$ are finite element (FE) analyses of the composite bicycle frames. In recent studies Liu and $\mathrm{Wu}[6]$ discussed about the fiber direction and stacking sequence design for a bicycle frame made of carbon/epoxy composite laminates. Under torsional, frontal, and vertical loadings, the normal and shear stresses with respect to the principal material coordinate system of each ply have been obtained from the finite element analyses. According to the maximum stress theory and the results of strength-to-stress ratios, optimal stacking sequence under three loading tests has been decided.

In the case of a complex structure to determinate the material constants of FRP is not trivial and not all the time the theoretical solutions are validated by practical results. The design of tubular parts must account of the material constants obtained on same geometric shape of the structure. Usually the lay-ups design has influence upon the mechanical characteristics.

The paper proposed a simple and original method for design and obtains the bent and variable cross-section tubular parts from carbon fibres composite materials in epoxy matrix. The case of a mountain bike composite handlebar was investigated in order to reduce its weight and to increase the mechanical characteristics. 


\section{Methods and materials}

The authors proposed in this study to simulate, characterize and test a tubular bent carbon fiber tube with variable section used as a bicycle handlebar. Tubular element made from carbon/epoxy was manufactured in the closed mould using an internal pressure. The composite materials are pressed on mould wall through an elastic mandrel and the resin excess was eliminated in the separation plane area. The two important tests for the handlebar, lateral bending test and torsion security test, provided by the EN 14766:2005 [7] standard were simulated by FE and for the lateral bending an experimental validation has been done. Determination of the apparent material constants corresponding to a single-layer equivalent model was done theoretically based on classical laminated plate theory. To validate the theoretical results in terms of material constants, from the same materials as for the handlebars, laminate plane samples were manufactured by vacuum forming technology and tested in uniaxial tensile test.

Considering the observations of the bicycle experts a new model of tubular part was designed. Similarly with a standard aluminium alloy handlebar the same diameter dimensions for the middle and the ends of the handlebar were maintained. The only changes are related to the design, the angle and the length of handlebar.

The virtual prototype was designed using the 3D CAD Solid Works software. The 3D prototype was submitted to a selective laser sintering (SLS) machine type Sinter Station 2000 (DTM Corp. USA). Through this procedure a prototype from plastic material (polyamide-PA), was obtained in short time. The plastic prototype was dimensionally verified on a mountain-bike.

For obtaining the composite material part a mould was manufacturing. Proposed solution required manufacturing of a metallic mould with a CNC processing centre. The mould was manufactured from aluminium alloy type 7075-T6. The mould is designed in 3D to the corresponding dimensions of the prototype by CATIA software [8]. The real part was obtained by milling on a CNC centre type Fadal VMC 4020 just running specific Solid CAM software.

The standard procedure consists in forming of carbon/epoxy tubular parts in a closed mould, the mandrel, being finally removed. The composite material, in non-polymerized state, was deposited on the elastic element and inserted into the mould. When an internal pressure is applied on the elastic element its volume increased, so the pressing of the composite material to mould's wall was realized. The mould is heated through its own plant or in heating room. After polymerization, the elastic element was removed and the composite material tube was released off the mould.

By removing the internal mandrel, there is the possibility to obtain composite materials tubes with variable wall thickness according to reinforced composite material thicknesses. The process eliminates the release problems of the manufactured composite tube from the mandrel after the polymerization process. Through this technology it was possible to obtain reinforced fibre composite materials with bent shape and having variable sections. In traditional processes, the solid mandrel used for manufacturing the tube, could not be removed after material polymerization, its central section being bigger than the end sections.

For manufacture of the composite handlebar following materials were used: carbon fibre twill fabric $\left(200 \mathrm{~g} / \mathrm{m}^{2}, 3 \mathrm{~K}\right)$ for carbon look Design, UD longitudinal elastic carbon fibre hose extensible from 20 to $50 \mathrm{~mm}$ (HT carbon fibre $9 \mathrm{~K}, 10$ ends $/ \mathrm{cm}$, flat width, welt 3 ends $/ \mathrm{cm}$ black double), carbon fibre hose $\pm 45^{\circ}$, to $12-40 \mathrm{~mm}$ diameter (96 threads Toray $3 \mathrm{~K}$, Weave double-braid), in epoxy resin type L285 and 256 the hardener from Hexion manufacturer. The mixing ratio is 100:40 parts by weight. It was respected the work condition according to the prescription of the resin producer.

The laminate configuration of the tube is $\left[0-90 / 0_{2} / \pm 45_{2}\right]$. At the middle of the pipe were laminated two supplementary lay-ups to $300 \mathrm{~mm}$ length UD longitudinal elastic carbon fibre hose extensible both the left and right sides from the middle point. 
During the manufacturing process the internal pressure in the mould was kept at 6 bar $(0.6$ $\mathrm{MPa}$ ) during the polymerization time. Manufacturing technologies of the composite materials usually use vacuum forming at a pressure of -0.9 bars. The proposed manufacturing method uses a 6 bar pressure that is almost 6.6 times bigger.

Easy machining is required in the separation plan area to remove the excess of resin from the surface.

The fibre volume fraction is $67.33 \%$ and the final weight is $95 \mathrm{~g}$ at $680 \mathrm{~mm}$ length. The weight reduction in comparison with an aluminium alloy handlebar with similar dimensions is about 2.6 times and 7.8 times for the case of steel handlebar. The result of the proposed innovative technology is the handlebar shown in Fig. 1, which actually represents a bent shape tube with variable cross-section made from carbon fibre in epoxy matrix.

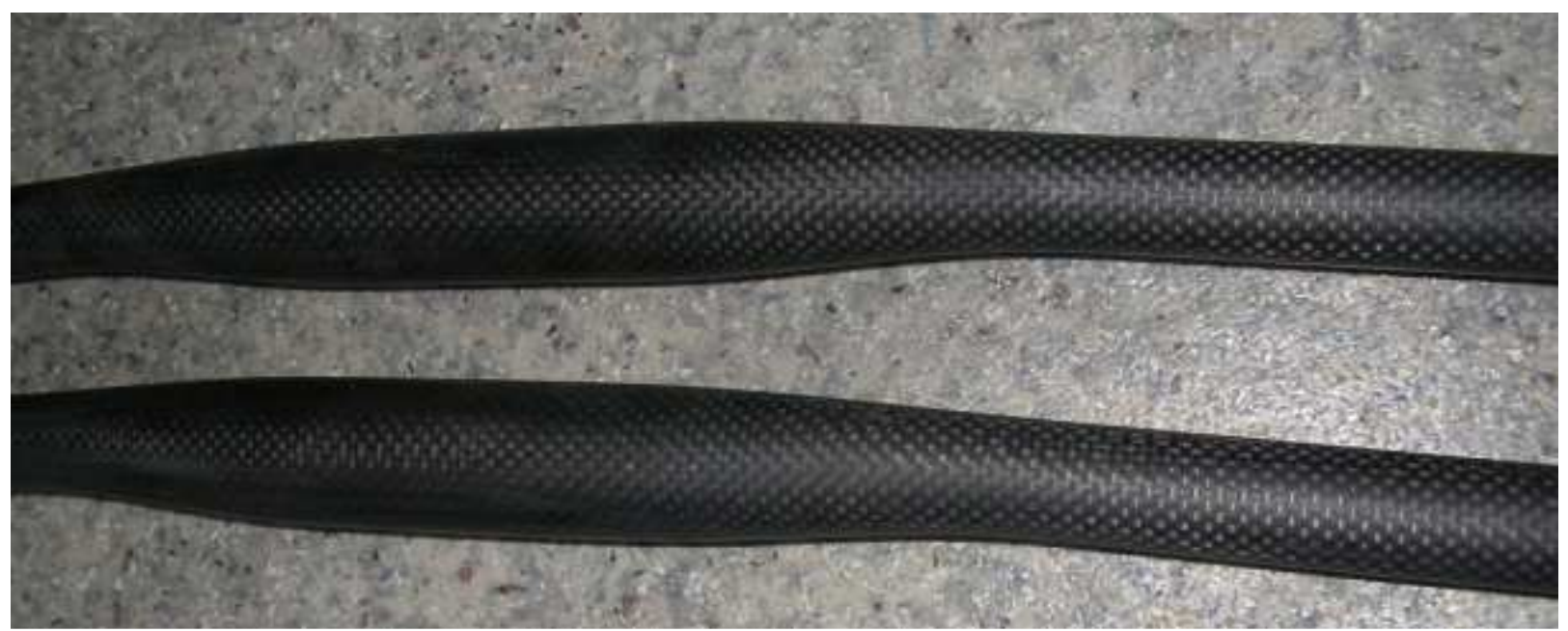

Fig. 1. Carbon fibre handlebars

Through the innovative solutions adopted, this technology allows producing tubular parts calibrated on the outside of the used mould. The reinforced material can be preferentially oriented in the requested direction, keeping its architecture after polymerization. The mould has been investigated to verify the dimensional accuracy if the initial data corresponds with design [9, 10]. The result is a well compressed composite material with an uniform structure, a high reinforcement degree, and good mechanical characteristics.

\section{Methods of analysis}

\subsection{Orthotropic material proprieties. Analytical and experimental approaches}

Knowing the real material parameters plays a key role in a reliable FE simulation of the composite handlebar. The manufactured material is an unsymmetrical (unbalanced) orthotropic laminate, experimental identification of mechanical properties being a complicated reverse engineering problem entailing several tests specifically designed for determining a given elastic constant that should be run always serially in order to reliably determine the value of that elastic constant on a statistical basis. Because of anisotropy, non-homogeneity and internal defects of the material, different testing procedures may even result in significantly different values of the same elastic constant [11-13]. Analytical models and numerical techniques are much simpler than experimental techniques. They are often based on highly idealized conditions. That may be openly in contrast with the real behaviour of the material. In the FE simulations the composite laminate has been considered a single-layer equivalent model with orthotropic behaviour characterized by a set of nine engineering constants.

Calculation of the material constants was done using a theory based on classical laminated plate theory software, for performing simple calculations, called The Laminator ver. 3.7. [14]. 
Based on single ply material proprieties and layup (stacking sequence) the software calculates the apparent laminate stiffness properties, Poisson and shear coupling coefficients and A, B, D stiffness matrices of the laminate.

Table 1. Designed ply material properties of carbon/epoxy composite

\begin{tabular}{|c|c|c|c|c|c|c|c|c|}
\hline Layer & $\begin{array}{l}\text { Mat. } \\
\text { ID }\end{array}$ & $\begin{array}{c}\text { Material } \\
\text { description }\end{array}$ & $\begin{array}{c}\mathrm{E}_{1} \\
{[\mathrm{GPa}]}\end{array}$ & $\begin{array}{c}\mathrm{E}_{2} \\
{[\mathrm{GPa}]}\end{array}$ & $\begin{array}{c}\mathrm{G}_{12} \\
{[\mathrm{GPa}]}\end{array}$ & $v_{12}$ & $\begin{array}{c}\text { Ply angle } \\
{\left[{ }^{\circ}\right]}\end{array}$ & $\begin{array}{c}\text { Thickness } \\
{[\mathrm{mm}]}\end{array}$ \\
\hline 1 & 1 & $\begin{array}{c}\text { Weave 2x2 } \\
\text { Twill }\end{array}$ & 53.6 & 55.2 & 2.85 & 0.042 & 0 & 0.25 \\
\hline 2 & 2 & UD & 181 & 10.3 & 7.17 & 0.28 & 0 & 1 \\
\hline 3 & 3 & UD & 181 & 10.3 & 7.17 & 0.28 & +45 & 0.5 \\
\hline 3 & 4 & UD & 181 & 10.3 & 7.17 & 0.28 & -45 & 0.5 \\
\hline
\end{tabular}

Table 1 shows the input data materials properties of individual plies according to the producer. Bi-directional ply was considered for calculation as two uni-directional layers having the half of thickness and orientation $+45^{\circ}$ and $-45^{\circ}$ respectively.

Apparent values of the material constants corresponding to the single-layer equivalent model obtained using the above presented stacking sequence is listed in Table 2. In this table the subscript 1 denotes the fibre axes of the second ply.

Table 2. Designed material constants of the single-layer equivalent model

\begin{tabular}{|c|c|c|}
\hline $\mathbf{E}_{\mathbf{1}}[\mathbf{G P a}]$ & $\mathbf{E}_{\mathbf{2}}[\mathbf{G P a}]$ & $\mathbf{E}_{\mathbf{3}}[\mathbf{G P a}]$ \\
\hline 67.7 & 24.61 & 24.61 \\
\hline $\mathbf{v}_{\mathbf{1 2}}$ & $\mathbf{v}_{\mathbf{1 3}}$ & $\mathbf{v}_{\mathbf{2 3}}$ \\
\hline 0.657 & 0.239 & 0.239 \\
\hline $\mathbf{G}_{\mathbf{1 2}}[\mathbf{G P a}]$ & $\mathbf{G}_{\mathbf{1 3}}[\mathbf{G P a}]$ & $\mathbf{G}_{\mathbf{2 3}}[\mathbf{G P a}]$ \\
\hline 11.32 & 9.93 & 9.93 \\
\hline
\end{tabular}

To validate the theoretical results, from the same materials as for the handlebars, laminate plates were manufactured by vacuum forming technology. Stacking sequence and reinforcement degree was kept the same. Five specimens in longitudinal and transverse direction with respect to the fibbers orientation of the second ply were manufactured from each plate and subjected to uniaxial tensile tests on an INSTRON 8862 tensile test machine. The samples dimensions and test procedure were compliant to EN ISO 527-4 and EN ISO 527-5 standards related to unidirectional and multidirectional fibre - reinforced plastic composites [15-16]. The ends of the specimens were reinforced with a $2 \mathrm{~mm}$ thick, 20-35 mm glass fabric TAB in order to avoid the slippage and breakage of specimens at clamping. The TABs were fixed on the specimens with a structural adhesive (3 M Scotch-Weld 9323 B/A). Prepared specimens were loaded to break, the strain values being acquired with a bi-axial extensometer. In Fig. 2 are shown the strain-stress curves of the two types of tested specimens. 


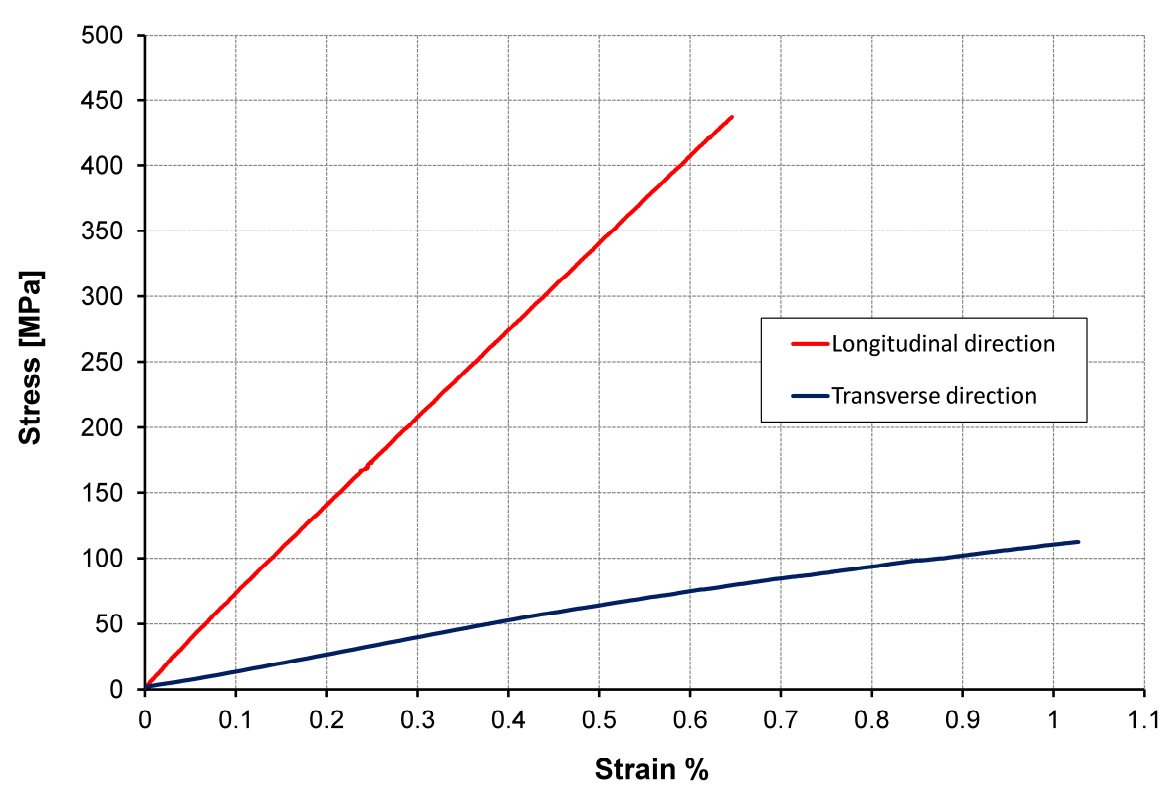

Fig. 2. Strain-stress diagram of longitudinal and transverse samples material.

The strain-stress diagram indicates an elastic behaviour of the carbon/epoxy composite

The experimentally obtained results (mean values) are presented in Table 3 and it can be noticed the good agreement with the above presented theoretical ones.

Table 3. Experimentally measured carbon/epoxy laminate material

\begin{tabular}{|c|c|c|c|c|c|}
\hline $\mathrm{E}_{1}[\mathrm{GPa}]$ & $\mathrm{E}_{2}[\mathrm{GPa}]$ & $v_{12}$ & $v_{23}$ & $\sigma_{\mathrm{u} 1}[\mathrm{MPa}]$ & $\sigma_{\mathrm{u} 2}[\mathrm{MPa}]$ \\
\hline 63.1 & 20.91 & 0.659 & 0.261 & 456.4 & 99.5 \\
\hline
\end{tabular}

The experimental mean tensile strength values of composite material indicate in one direction similar values like steel. This considering that the density of the composite is 7 times smaller than steel.

\subsection{Finite element simulation}

The EN 14766:2005 standard provides the safety requirements and test methods for mountain-bicycles. There are two important tests for the handlebar, one called lateral bending test and one torsional security test. The finite element method and ANSYS Workbench [17] software was used to analyse the structural behaviour of the composite handlebar subjected to the load cases requested by the standard. Static structural analysis and linear elastic proprieties were considered in this study. In the FE analyses of the handlebar the mechanical constants of orthotropic, single-layer equivalent model presented in Table 2 were used. Lateral bending test presumes a static test of the handlebar-stem assembly that is permanently connected with the grips portion of the handlebar in a plane perpendicular to the stem axis. The assembly is loaded with a force of $1000 \mathrm{~N}$ at a distance of $50 \mathrm{~mm}$ from the free end of the handlebar. This force will be maintained for $1 \mathrm{~min}$. The torsion security test presumes clamping of the handlebar stem securely in a fixture to the minimum insertion depth and with its axis vertical and applying a torque of $80 \mathrm{Nm}$ about the centre-line of the stem-clamp. The torque is divided equally by vertically, downward forces applied to both sides of the handlebar. In Fig. 3, it shows the maximum principal stress distribution of the lateral bending test. 

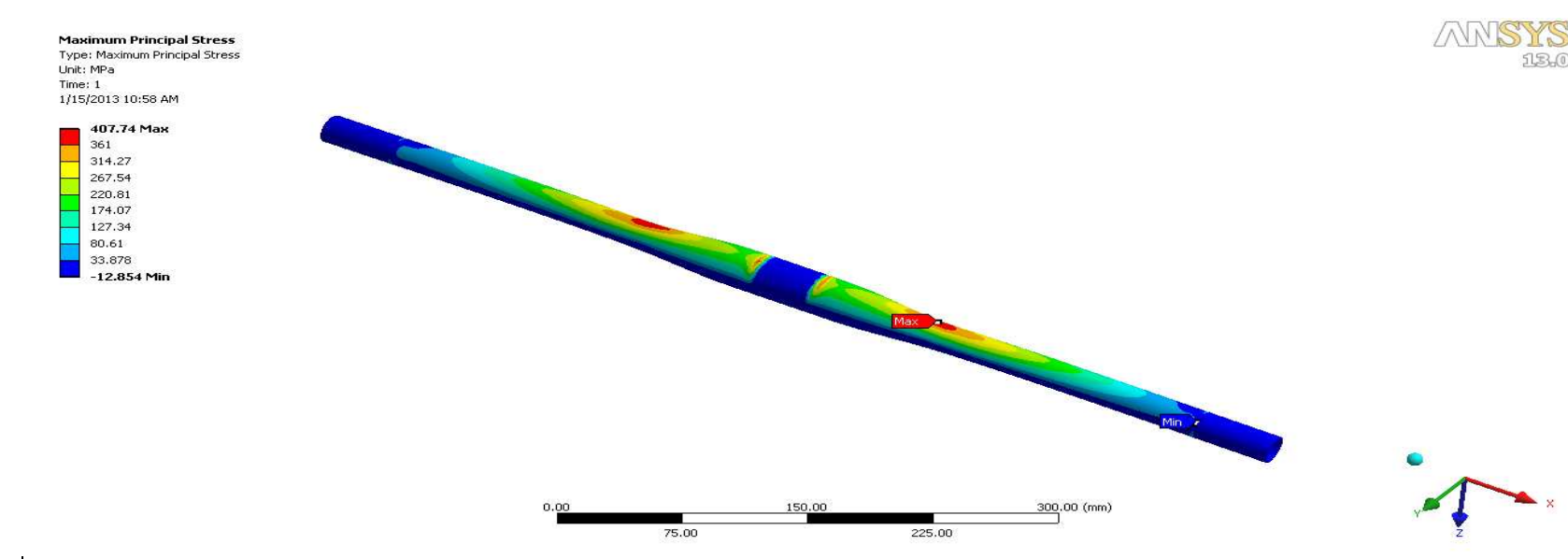

Fig. 3. Maximum principal stress distribution in the handlebar: lateral bending test
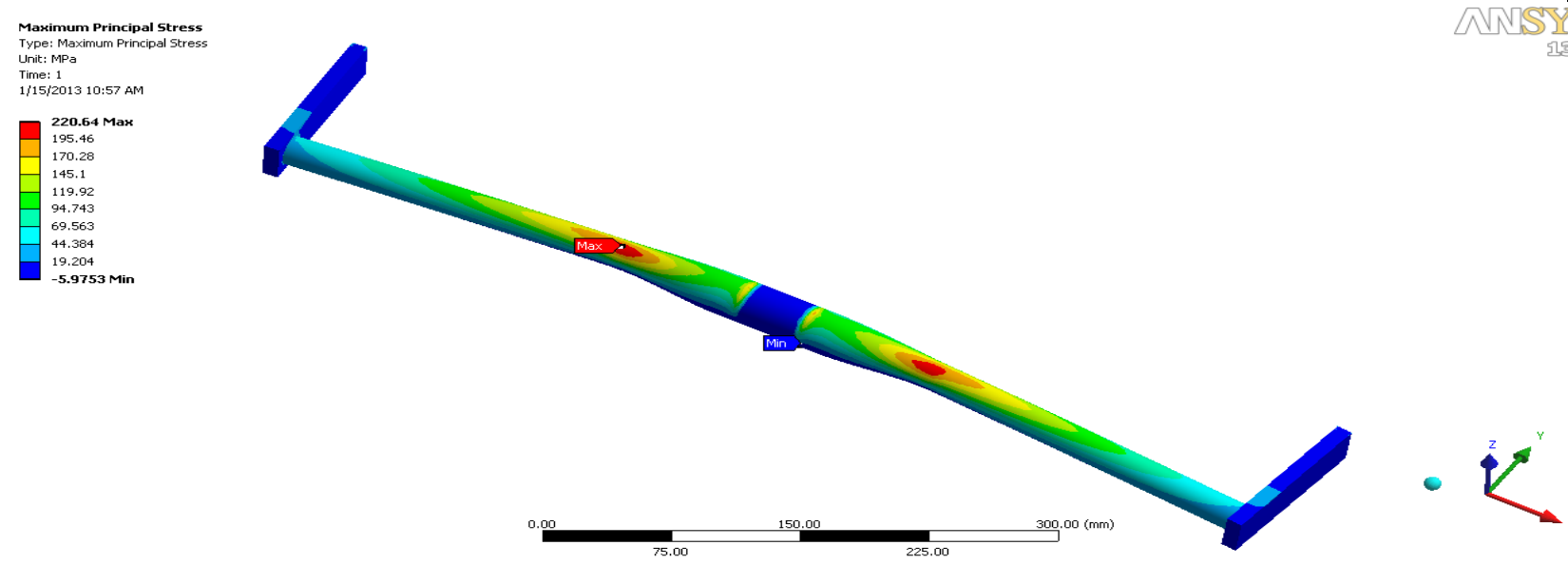

Fig. 4. Maximum principal stress distribution in the handlebar: torsion security test.

Fig. 4 shows the maximum principal stress distribution of the torsion security test. The FE results confirm that the carbon/epoxy composite handlebar undergoes maximum stress values of $408 \mathrm{MPa}$ in case of lateral bending and $221 \mathrm{MPa}$ for the torsion test. Analysing the maximum principal stress, its direction coinciding with the direction 1 (fibres direction of the second ply), the maximum values are under the ultimate stress experimentally measured of $456 \mathrm{MPa}$. Maximum deflection for the lateral bending test was $11.5 \mathrm{~mm}$.

\subsection{Test of handlebar}

The epoxy/composite handlebar manufactured with the technology above described was tested for the critical load case called lateral bending test. As presented in the simulations the torsion test produces lower stress value that the bending tests. When tested at lateral bending, there shall be no cracking or fracture of the handlebar, stem or clamp-bolt and the permanent set measured at the point of application of the test force shall not exceed $15 \mathrm{~mm}$. Experimental set-up that reproduces the bending test requirements is shown in Fig. 5. The handlebar is simply supported and connected by clamping with a commercial aluminium stem coupled to a loading frame through a force transducer (HBM-U2B-10KN). Strain at outer surface near the clamping area was measured by a strain gauge (Vishay C2A-06-125LW-120). 


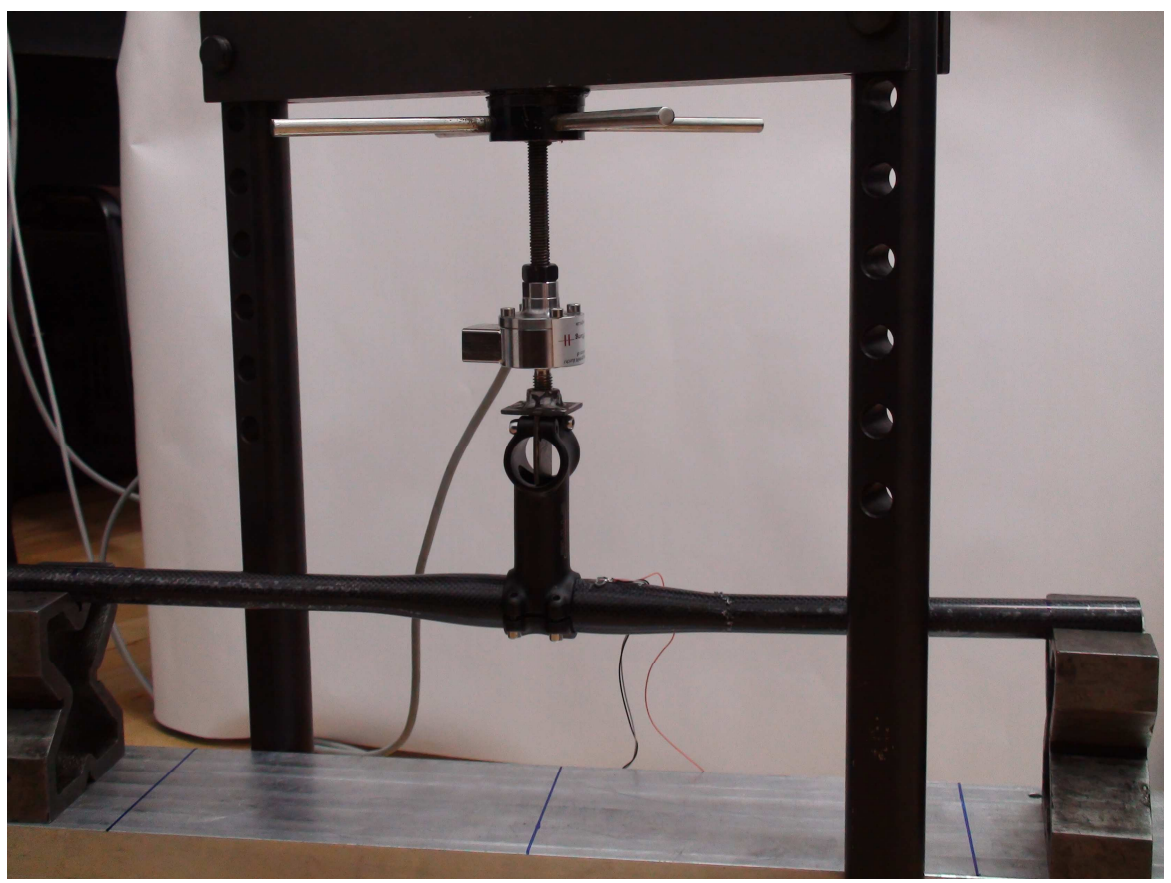

Fig. 5. Experimental set-up for handlebar lateral bending test.

Performing the test it could be noticed that the handlebar meet the safety requirements, being enough strong to undergo the total applied force of $2000 \mathrm{~N}$. Increasing the force till failure, it could be noticed that around $2100 \mathrm{~N}$ some fibres broke, the ultimate force being $2230 \mathrm{~N}$. Broken area coincides with that obtained in the FE simulation.

The maximum loading force obtained in the experimental analysis in case of lateral bending test validates the numerical simulation and in the same time the material properties determined both analytically and also by the tensile test. Strain values registered by the strain gauge were closed with those obtained from the numerical simulation. The safety factor is small, the ultimate force being close to the standard requirement.

\section{Summary}

The proposed method allows manufacturing of the bent shape tubes with variable crosssection from fibre reinforced composites. The original procedure by using an inner pressurized elastic mandrel is able to assure constant pressure upon the reinforcement material, the result being a compact composite, good pressed with an optimum reinforcement degree related the materials used. Traditional methods that use a rigid mandrel manufacturing of bent tubes with variable crosssection as the presented handlebar couldn't be applied due to the fact that the mandrel cannot be released from the composite tube. The obtained handlebar has a significantly reduced weight $(95 \mathrm{~g})$ in comparison with aluminium alloy handlebar with the same dimensions $(\sim 250 \mathrm{~g})$. The procedure is relatively simple to put in practice and the costs are reduced.

The materials constants, experimentally obtained, are in good agreement with the theoretical results based on the classical laminated plate theory that considered the composite material as a single-layer equivalent orthotropic model.

The FE results of the two important tests for the handlebar namely lateral bending test and torsion security test, requested by the safety regulations for mountain-bicycles, confirm that the carbon/epoxy composite handlebar undergoes maximum principal stresses of $408 \mathrm{MPa}$ in case of lateral bending and $221 \mathrm{MPa}$ for the torsion test. Analysing the maximum principal stress values, its direction coinciding with the fibres direction of the second ply, the maximum value was under the ultimate stress experimentally measured. Performing the lateral bending test on the manufactured handlebar it could be noticed that the handlebar meets the safety requirements, being enough strong to undergo the total applied force of $2000 \mathrm{~N}$. The maximum loading force obtained in the 
experimental analysis has validated the numerical simulation and, in the same time, the determined material characteristics. The safety coefficient is small, reason why, according to the designer options, the handlebar can be strengthened by additional inner plies added in the maximum stressed area.

\section{Acknowledgments}

This paper was supported by the projects: ${ }^{1}$. "Development and support of multidisciplinary postdoctoral programmes in major technical areas of national strategy of Research - Development Innovation" 4D-POSTDOC, contract no. POSDRU/89/1.5/S/52603, project co-funded by the European Social Fund through Sectoral Operational Programme Human Resources Development 2007-2013 and 2. PRiDE project, contract no. POSDRU/89/1.5/S/57083, project co-funded from European Social Fund through Sectoral Operational Program Human Resources 2007-2013 for logistic and materials.

\section{References}

[1] Barbero EJ. Introduction to Composite Materials Design. Boca Raton: Taylor \& Francis; 1999.

[2] Gay D, Hoa SV. Composite Materials: Design and Applications, Second Edition. Boca Raton: CRC Press; 2007.

[3] Vasiliev VV, Morozov EV. Mechanics and Analysis of Composite Materials. London: Elsevier Science; 2001.

[4] Peterson LA, Londry KJ. Finite-element structural analysis: a new tool for bicycle frame design. Bicycl Mag Newsl 1986;5(2).

[5] Lessard LB, Nemes JA, Lizotte PL. Utilization of FEA in the design of composite bicycle frames. Composites 1995;26(1):72-4.

[6] Liu J-CT, Wu HC. Fiber direction and stacking sequence design for bicycle frame made for the carbon/epoxy composites laminates, Mater Design 2010;31:1971-1980.

[7] EN 14766, Mountain bicycles- Safety requirements and tests methods, 2005.

[8] CATIA V5-6R2012 France: Dassault Systèmes; 2012.

[9] Morovič L, Pokorný P. Optical 3D Scanning of Small Parts, Advanced Materials Research, Vols. 468-471 (2012) pp. 2269-2273, Trans Tech Publications, Switzerland, doi:10.4028, www.scientific.net/AMR.468-471.2269.

[10] Šugár P, Šugárová J, Morovič L, Zemko P, Analysis of dimensional accuracy of spun parts by Taguchi approach, Applied Mechanics and Materials, Vols. 217-219 (2012) pp 2423-2426, Trans Tech Publications, Switzerland, doi: 10.4028, www.scientific.net/AMM.217-219.2423.

[11] Genovese K, Lamberti L, Pappalettere C. A new hybrid technique for in-plane characterization of orthotropic materials, Experimental Mechanics 2004; 44(6):584-592.

[12] Kosa G, Bercu M, Grecu V. Longitudinal elastic waves in deformed carbon nanotubes, Romanian journal of information science and technology 2011; 14(4):324-333

[13] Kollar L, Springer GS. Mechanics of composite structures. New-York: Cambridge University Press; 2003.

[14] The Laminator 3.7: Lindell M. www.thelaminator.net; 2011.

[15] ISO 527-4 2: 1997, Plastics - Determination of tensile properties. Test conditions for multidirectional fiber - reinforced plastic composites.

[16] ISO 527-5 A, B: 1997. Plastics - Determination of tensile properties. Test conditions for unidirectional fiber - reinforced plastic composites.

[17] ANSYS 12.0. USA: ANSYS Inc.; 2009. 